\title{
A Single Phase Current Source PFC Converter Based on UC3854*
}

\author{
Jianbo Yang1, Weiping Zhang ${ }^{2}$, Faris Al-Naemi ${ }^{1}$, Xiaoping Chen ${ }^{2}$ \\ ${ }^{1}$ Materials and Engineering Research Institute (MERI), Sheffield Hallam University (SHU), Sheffield, UK \\ ${ }^{2}$ Lab of Green Power \& Energy System (GPES), North China University of Technology (NCUT), Beijing, China \\ Email: jumbo-yang@hotmail.com
}

Received September, 2012

\begin{abstract}
A novel high-power-factor Buck type converter with average current control based on UC 3854 is proposed. The input current is directly controlled by average current control scheme to deliver sinusoidal input current and to gain a high power factor. The practical results, which illustrate the proposed control philosophy, were obtained from a $120 \mathrm{~W}$ $\mathrm{AC} / \mathrm{DC}$ Buck type converter. The power factor can reach 0.97 .
\end{abstract}

Keywords: Current Source; PFC; UC3854

\section{Introduction}

With the extensive application of high frequency power supply, severe distortions will be introduced into the input current. Thus, the input current which contains a lot of harmonics will degrade the Power Factor. Therefore, high power factor techniques are required [1].

PFC can be divided into two main types by the output. One is voltage source PFC, and the counterpart is current source PFC (power factor correction). However, the main research work has been focusing on the voltage source PFC for quite a long time. The reason is that capacitor used in voltage source PFC as an energy storage element is smaller and cheaper than inductor used in current source PFC. Therefore, the research and application of the current source PFC is restricted [2,3]. Nevertheless, the energy storage problem of current source PFC is going to be solved by the development of superconducting technology [4]. As a result, the current source PFC will be more popular. With the research going deep, the reactive power compensation of the power system [5], active electric power filter [6], solar and wind energy and other renewable energy, which are based on current source $\mathrm{PFC}$, are developing rapidly.

A $120 \mathrm{w}$ single phase current source PFC based on Buck type converter has been developed in this paper. With the directly control scheme, the output current can be kept at $1 \mathrm{~A}$. Also, the output voltage is $200 \mathrm{~V}$ which is lower than the input voltage $220 \mathrm{~V}$ (RMS), which over-

*Project supported by Natural Science foundation of China (N0. 51277004). The Importation and Development of High-Caliber Talents Project of Beijing Municipal Institutions (No.IDHT20130501) comes the disadvantage of the Boost PFC.

\section{Power Stage}

\subsection{Circuit Configuration}

Topologies of the two kinds of PFC mentioned in chapter 1 are actually dual with each other, which is shown is Figure 1[7]. The power stage of single phase current source PFC can be suggested in Figure 1(b). One problem can be found easily is that the input power supply is an $\mathrm{AC}$ current source which is not the same as the AC voltage source usually used in the normal life. To counteract this inconsistency, an input inductor can be employed, as shown in Figure 2. The problem is solved as the input $\mathrm{AC}$ voltage supply and the input inductor can form an analog AC current source. Therefore, the proposed single phase current source PFC base on Buck topology can be obtained.

The input voltage and input current can be expressed as follows when the PFC function is accomplished

$$
u_{m} \sin w t * i_{m} \sin w t=u_{\text {out }} I_{o}
$$

The output voltage is suggested as:

$$
u_{\text {out }}=\frac{u_{m} i_{m}}{I_{o}} \sin ^{2} w t=\frac{u_{m} i_{m}}{2 I_{o}}(1-\cos 2 w t)
$$

There exists a low frequency component which is twice of line frequency in the output voltage. If only an inductor servers for filter to file this low frequency ripple, the size of the inductor at the DC side will be obviously large. To reduce the size of the inductor at the output side $\left(\mathrm{L}_{0}\right)$, a LC parallel resonance net which is in series with 
the output inductor is employed. Figure 3 presents the suggested converter.

The parallel resonant filter prevents the second harmonic distortions presenting at the output current. Thus, the specifications for the filter design are resonant frequency and $Q$ factor. The principles can be given as,

$$
\left\{\begin{array}{l}
w_{o}=2 \pi f_{0}=\frac{1}{\sqrt{L_{1} C_{1}}} \\
f_{0}=2 \times f_{l} \\
Q=\frac{R_{e}}{w_{0} L_{1}}
\end{array}\right.
$$

The inductor should be large enough to attenuate the resonant current which may cause the inductor magnetic saturation.

\subsection{Operation Principles}

The parallel net shown in Figure $\mathbf{3}$ is just used to filter

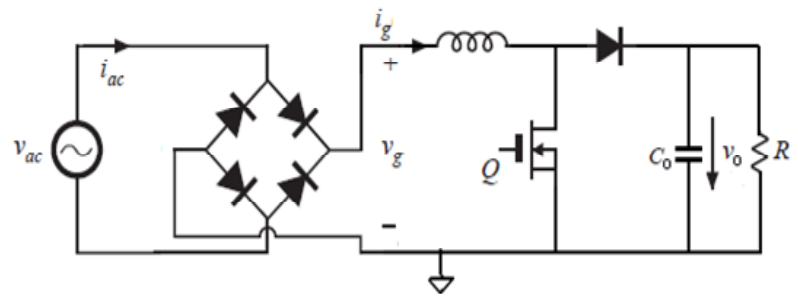

(a) Voltage source PFC out the two time of line-frequency harmonic of the output voltage. The design of the net is provided by (3). Thus, the net can be out of concern when the operation principles of the proposed converter are discussed. Therefore, the operation discussed in this paper is based on the configuration shown in Figure 2. However, the circuit used in the experiment is based on Figure 3.

When the converter operates as a PFC Preregulator, the input current will follow the input voltage, which can be presented as $i_{m}|\sin w t|$. The operation principles of the proposed converter shown in Figure 2 are illustrated in Figure 4. As shown, the average voltage over $L_{0}$ is zero in steady state. Thus, the average voltage over $C_{0}$ is input voltage, $V_{m}|\sin w t|$.

1) When $Q$ is turned on, $D 1$ is reverse-biased. The current flows through the capacitor is

$$
i_{C_{0}}=I_{o}-i_{m}|\sin w t|<0
$$

$I_{o}$ is the output current which is thought to be constant. $C_{0}$ is discharging and transfer energy to load and $L_{2}$.

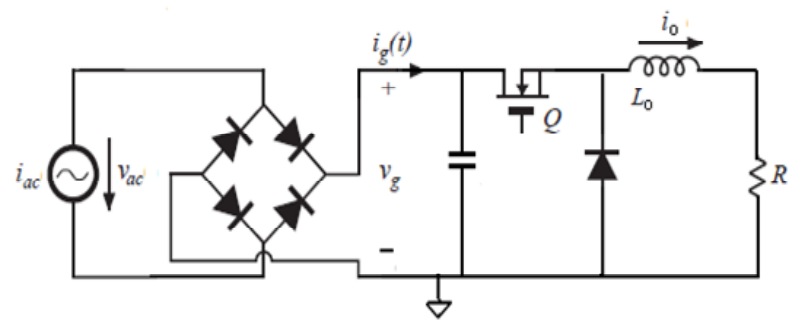

(b) Current source PFC

Figure 1. Two different type PFC circuits.

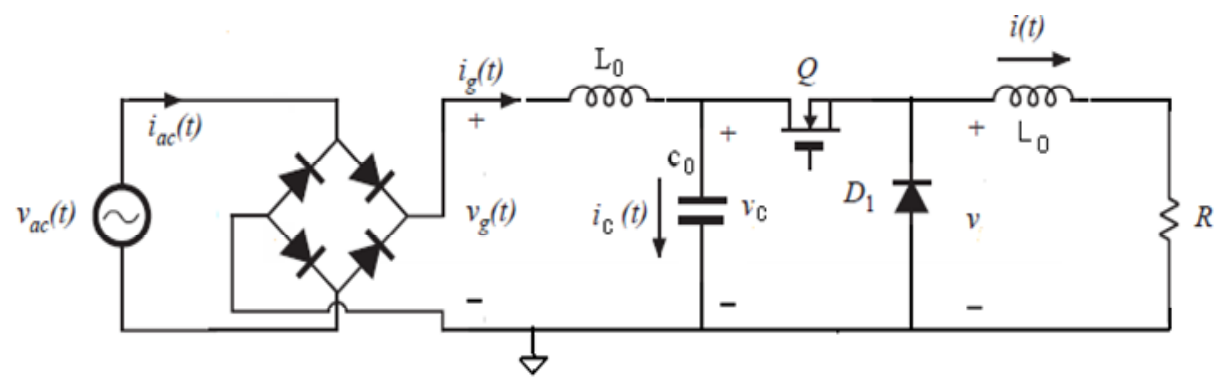

Figure 2. Proposed converter.

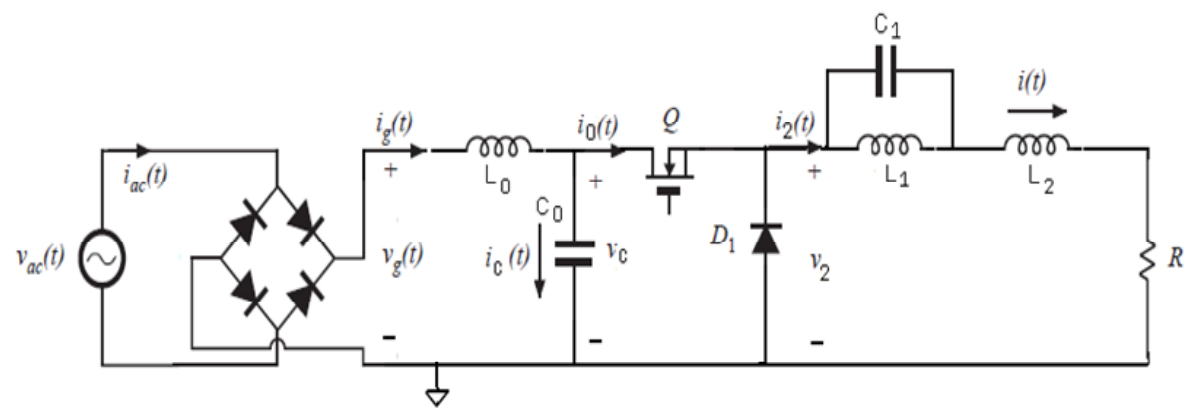

Figure 3. A proposed converter with parallel net. 
2) When $Q$ is turned off, $D_{1}$ is forward-biased. The converter is divided into two parts as shown in Figure 4(b) the current, $i_{m}|\sin w t|$, flows through the capacitor $C_{0} . C_{0}$ absorbs energy from the input. $\mathrm{L}_{2}$ is discharging and supporting output.

It is clear that the inner energy balance component is $\mathrm{C}_{0}$, which is different from the conventional voltage source PFC. In voltage source PFC converter, the energy balance components is usually inductor.

\section{Control Scheme}

\subsection{Control Block}

Figure 5 depicts the details of the average current control strategy used for the proposed converter. As illustrated, the average current control consists of two loops structure. The outer loop is designed for maintaining the output constant. The inner loop is implemented to force the input current tracking the input voltage, which can obtain high power factor. The difference lies in that the output single is sensed from the output current other than the output voltage due to the current source characteristic. Figure 6 depicts the details of the entire proposed system. As illustrated, the input and output current are both sensed by the inner loop sensed resistor and a current transducer of the outer loop. For this average current control strategy, a popular control chip UC3854 can be implemented here for the proposed converter.

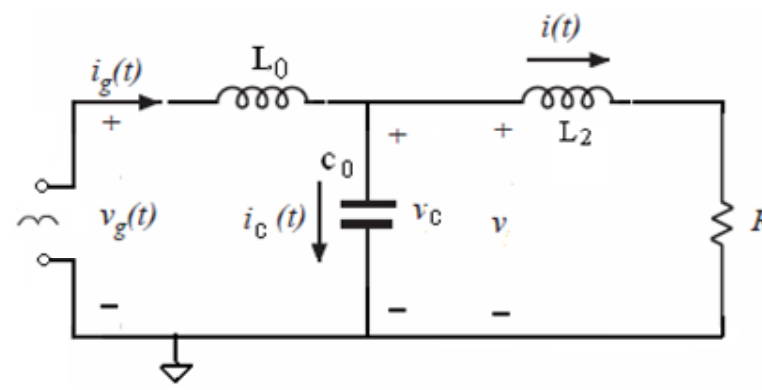

(a) Q is turned on, $D_{1}$ is reverse-biased

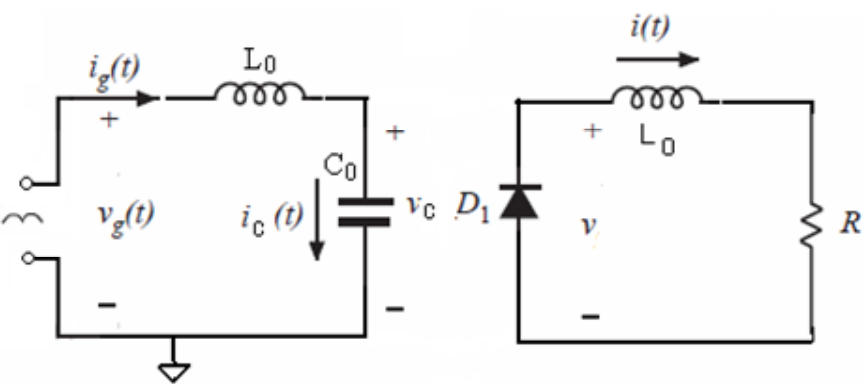

(b) Q is turned off, $\mathrm{D}_{1}$ is forward-biased

Figure 4. Operation principles.

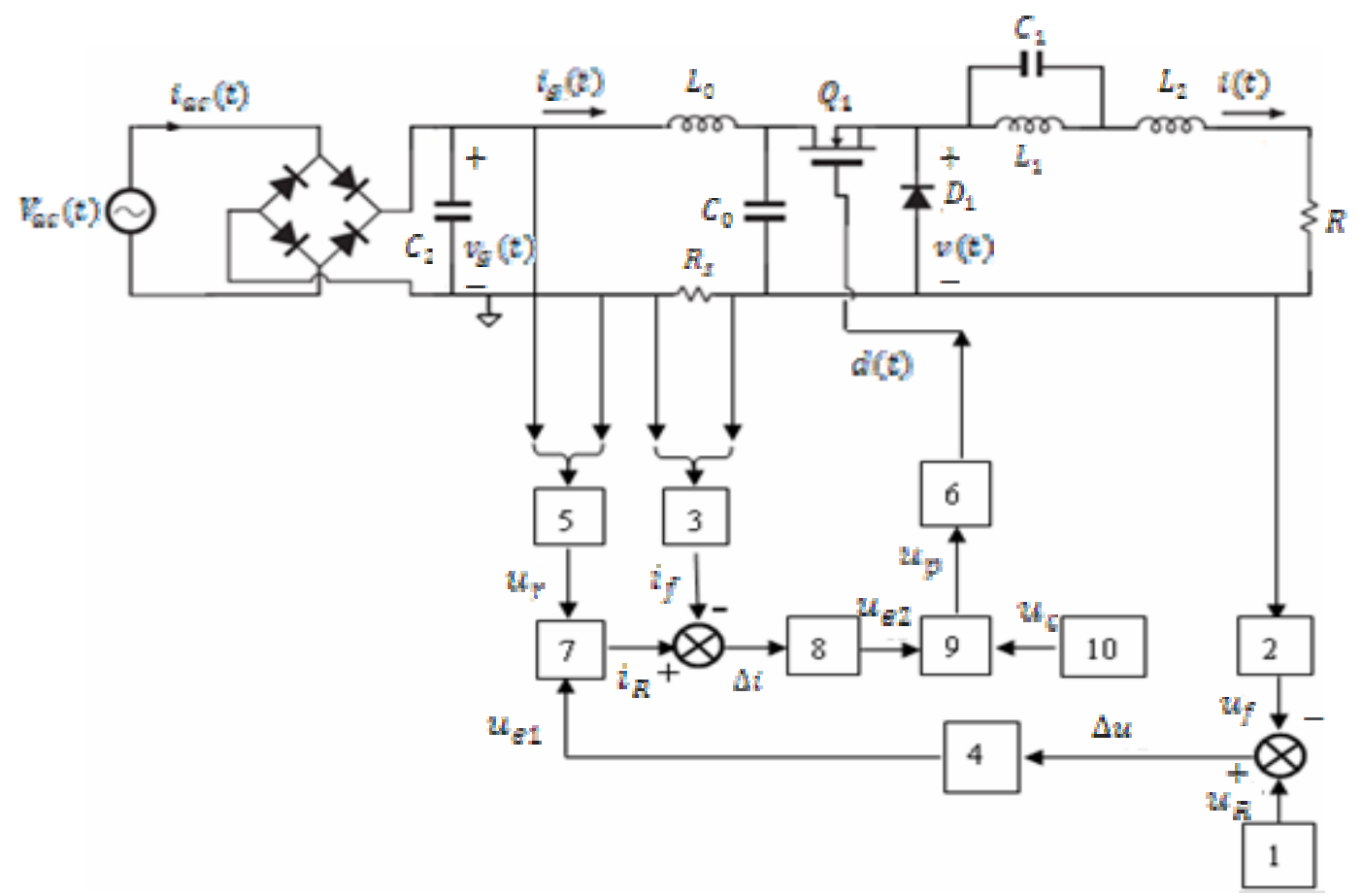

Figure 5. Block diagram of the control scheme-double loop: 1- DC voltage reference; 2- DC output current sensing; 3- AC input current sensing; 4- voltage regulator; 5- input voltage sensing; 6- drive circuit; 7- multiplier; 8- current regulator; 9PWM comparator; 10- sawtooth wave generator. 
As depicted in Figure 6, the average current control has the conventional double-loop structure. However, the difference lies in the output sensing. As the output is a constant DC current that works as a DC current source. Thus, the output current is sensed by a current transducer. Then, this sensed signal is transferred to voltage which is compared to the reference voltage to make the output stable. This makes sure that the conventional PFC IC can be used in this proposed converter.

There are two operational amplifiers and two corresponding compensation network, which is the same as the conventional average current control scheme used for the voltage source PFC converter.

\subsection{Switching Current Analysis}

The power stage of the converter has two different configurations shown in Figure 4. If the input current is as- sumed to track the input voltage correctly and the output current can be kept as a constant value, then the waveforms of the proposed converter can be depicted as Figure 7 the output current of the proposed converter will be higher than the peak of output current. This is very similar with the relationship of the input voltage and output voltage of the single phase voltage source Boost PFC.

The modulating voltage and the carried voltage are both generated by the UC3854, which are used to generate the switch control signal [8]. $u_{s}$ is sinusoidal and is compared with the triangular voltage, $u_{c}$ When $u_{s}>u_{c}$, a turn-on signal is generated to make the switch open. When $u_{s}<u_{c}$, Q will be turned off.

The switch current varies in accordance with the ontime of the switch. Further analysis can be made that the switch current can be expanded by Fourier series as,

$$
i_{Q}=\frac{a_{0}}{2}+\sum_{n=1}^{\infty} a_{n} \cos n w t
$$

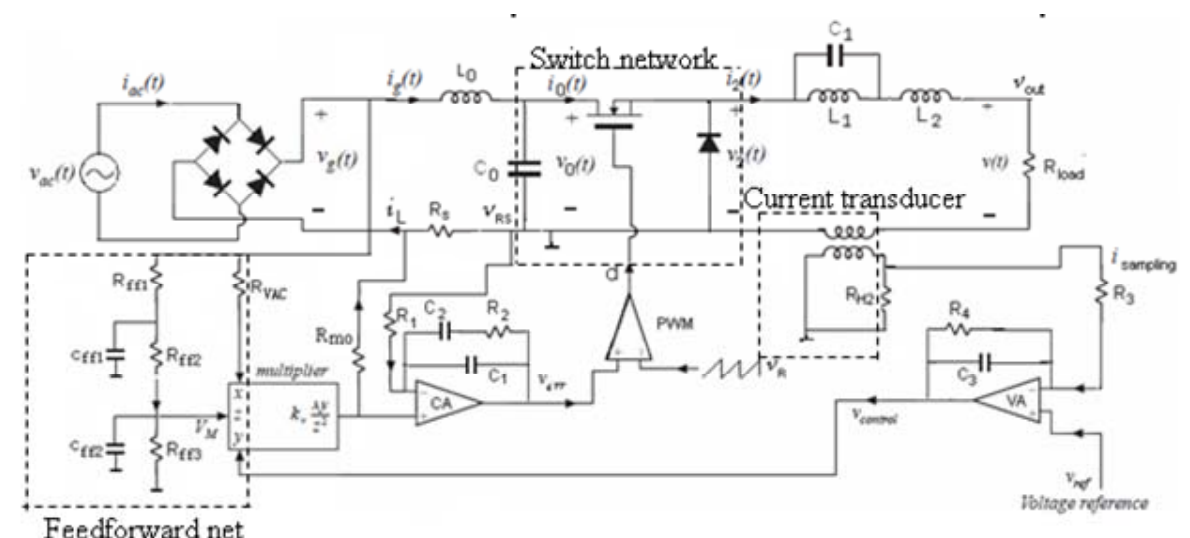

Figure 6. Proposed “double current loop” control strategy,

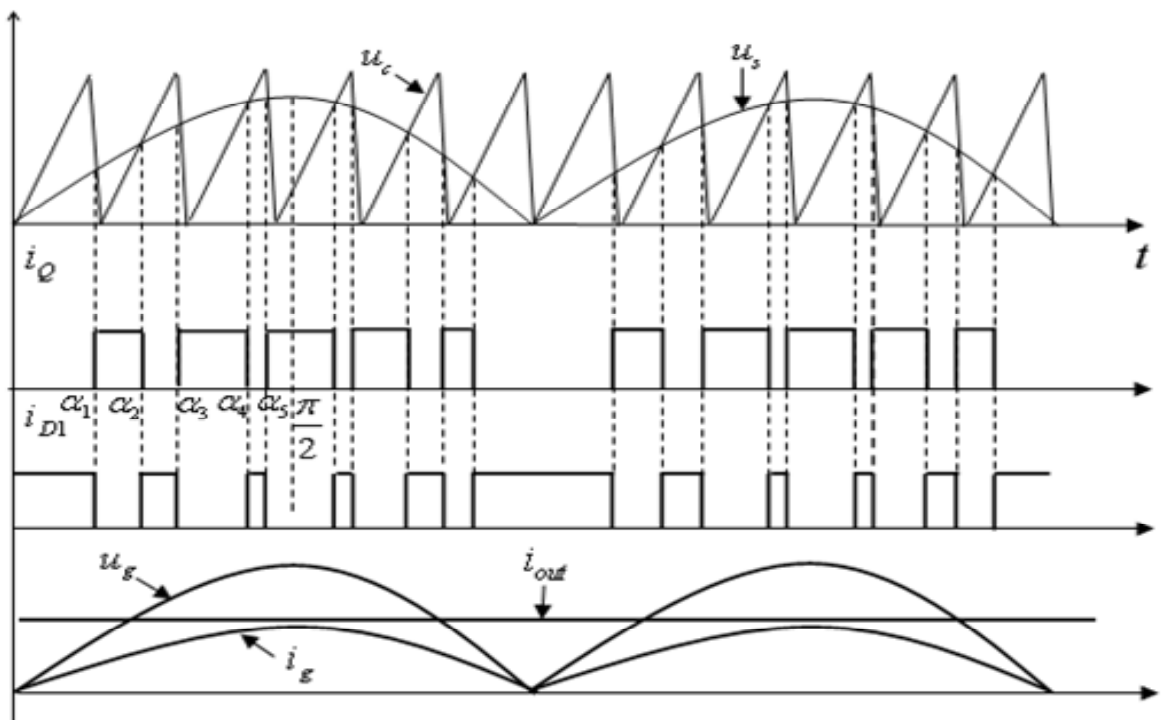

Figure 7. Waveforms of proposed converters: $u_{s}$-modulating wave; $u_{c}$-carrier wave; $i_{Q}$-switch current; $i_{D 1}$-diode current. 
$\alpha_{1} \sim \frac{\pi}{2}$ in Figure 7 mean the conduction angles in a quarter of the line cycle. Consequently, the switch current can be expressed as,

$$
\begin{aligned}
i_{Q}=\frac{2}{\pi} I_{\text {out }}+\sum_{n=1}^{\infty} & {\left[\frac { 4 } { n \pi } I _ { \text { out } } \left(1+\sin n \alpha_{2}+\sin n \alpha_{4}\right.\right.} \\
& \left.\left.-\sin n \alpha_{1}-\sin n \alpha_{3}-\sin n \alpha_{5}\right) \cos n w t\right]
\end{aligned}
$$

The fundamental wave and other harmonics of the switch current are decided by the conduction angle, which is decided by the conjunction of the $u_{c}$ and $u_{s}$.

\section{Results}

\subsection{Simulations}

Simulations using Pspice has been carried out. As shown in Figure 8, the double-loop control structure is identical to the theoretical analysis shown in Figure 6. The input voltage was set to be $220 \mathrm{~V}$ (RMS) with $50 \mathrm{~Hz}$ frequency. The switch frequency is $100 \mathrm{kHz}$. The input power is 200 $\mathrm{W}$ and the output power is $170 \mathrm{~W}$. The efficiency is about $85 \%$.

The results are shown below and prove that the power factor can be about 0.97 and the output current can be constant.

\subsection{Experiments}

A $120 \mathrm{~W}$ prototype has been was proposed for verifying the features of the converter. The experimental results are in coincidence with the simulations ones. The results are shown in Figure 10.

\section{Conclusions}

A high power factor single phase current source converter is proposed in this paper. Input current is directly controlled by the average current control scheme based on UC 3854, which forms a particular "double-currentloop" control programme. Moreover, a parallel resonant filter is employed to downsize the output inductor. The proposed converter can deliver a constant DC output current which can function as a DC current source. In addition, it does not require that the output voltage has to be higher than the input voltage.

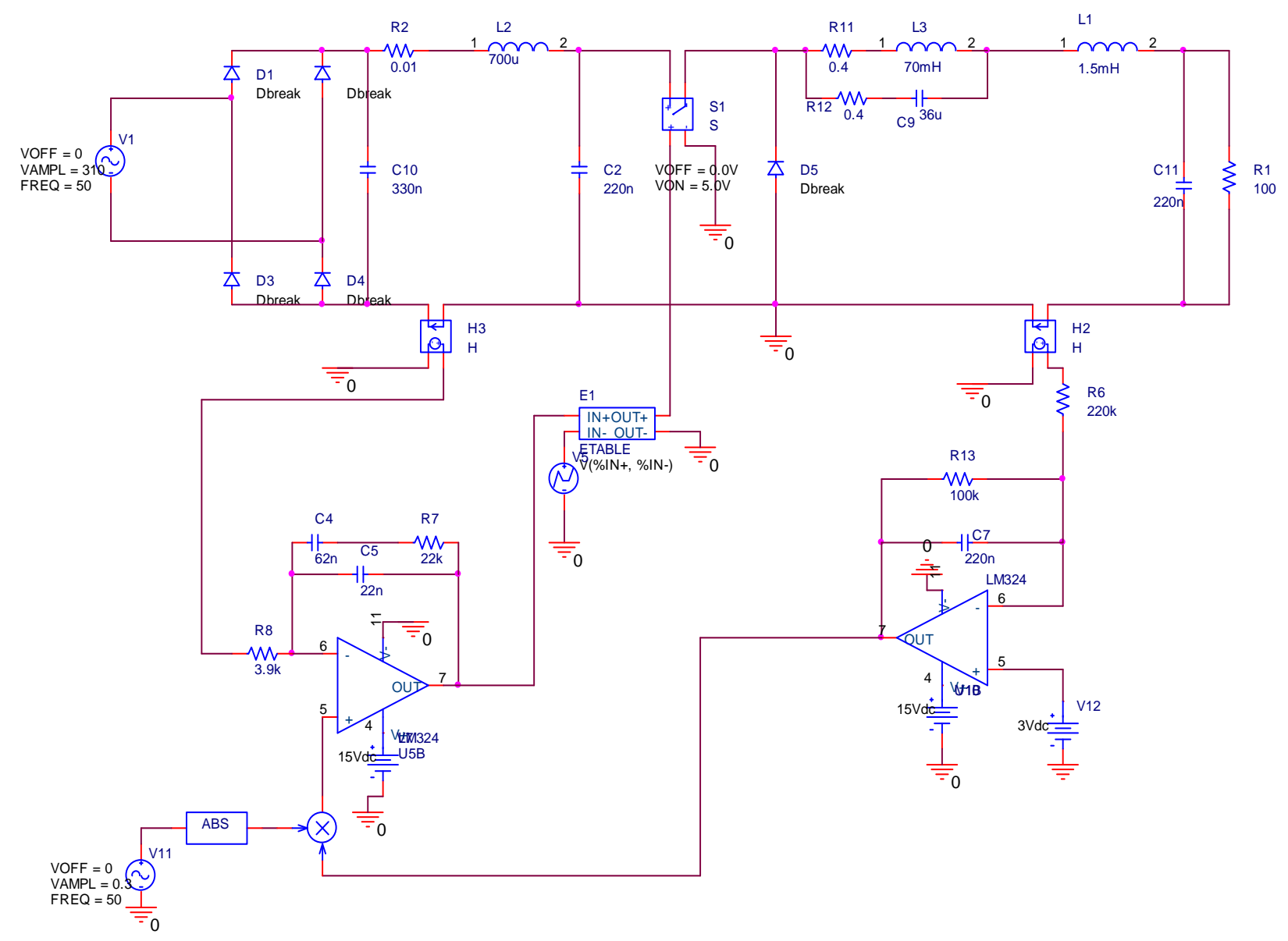

Figure 8. Pspice simulation block. 


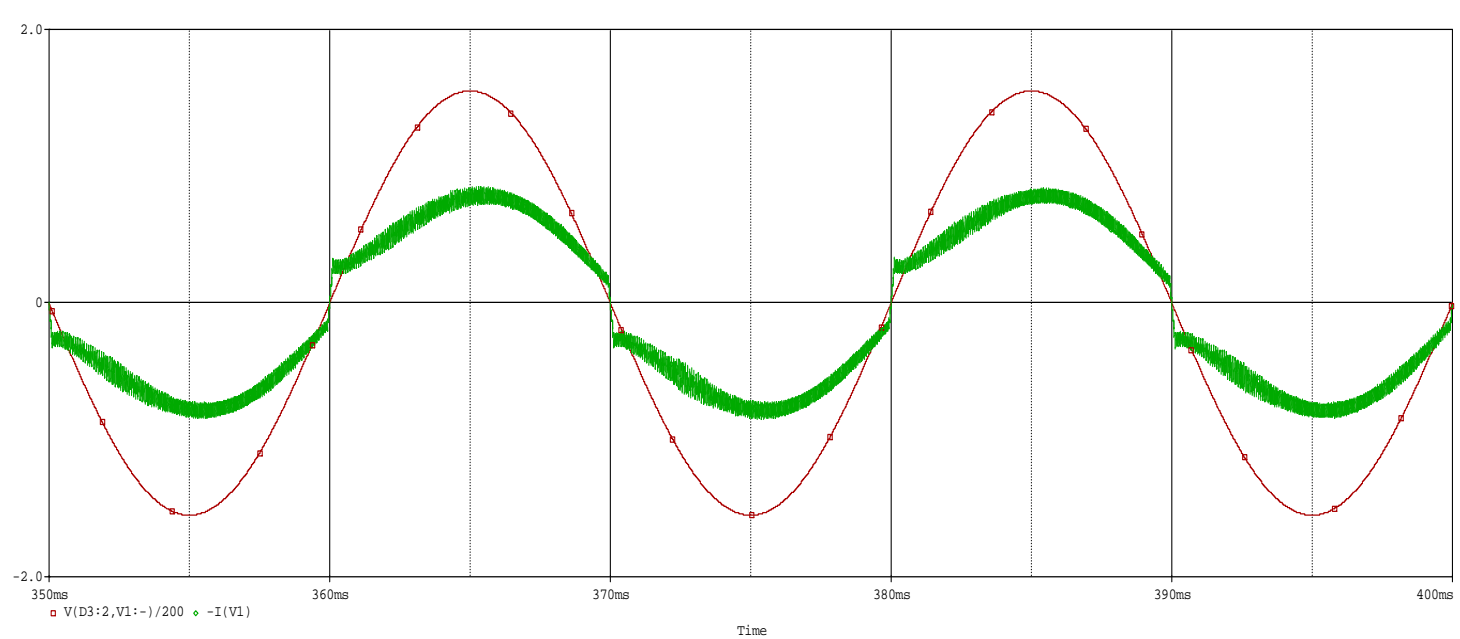

(a) Input voltage: $310 \mathrm{v}$ (peak) ; Input current: $1.3 \mathrm{~A}$ (peak)

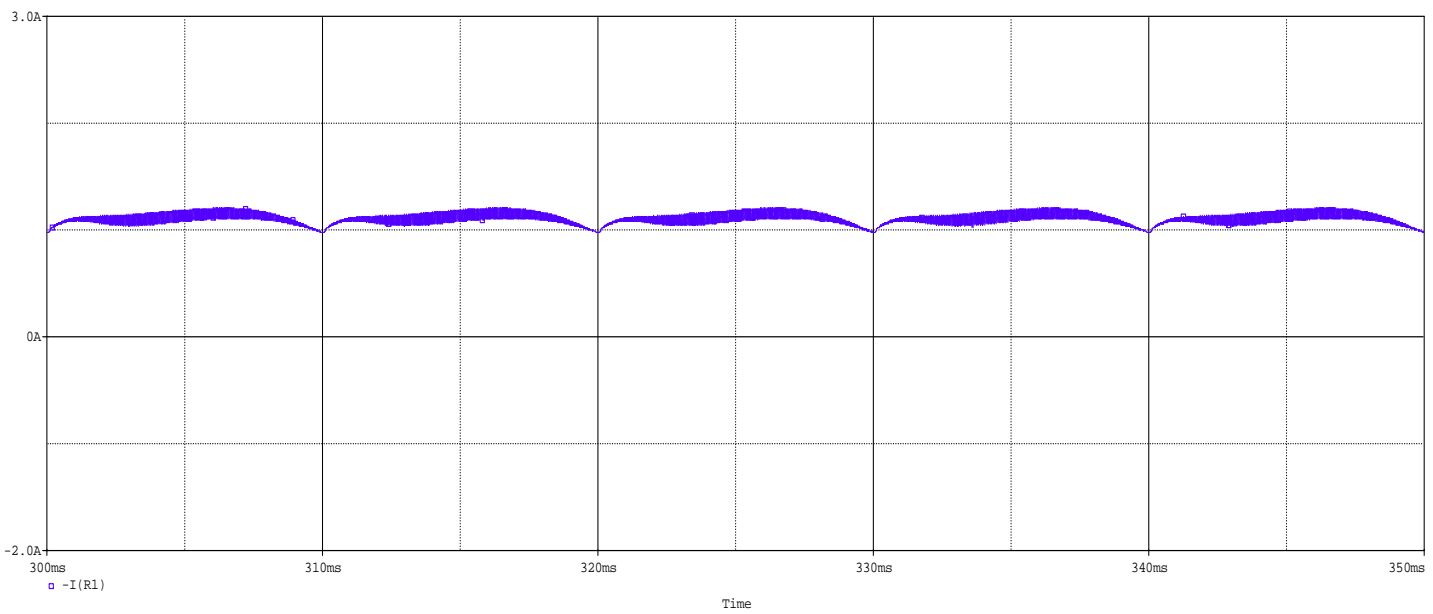

(b) Output current: 1.4A

Figure 9. Simulation results.
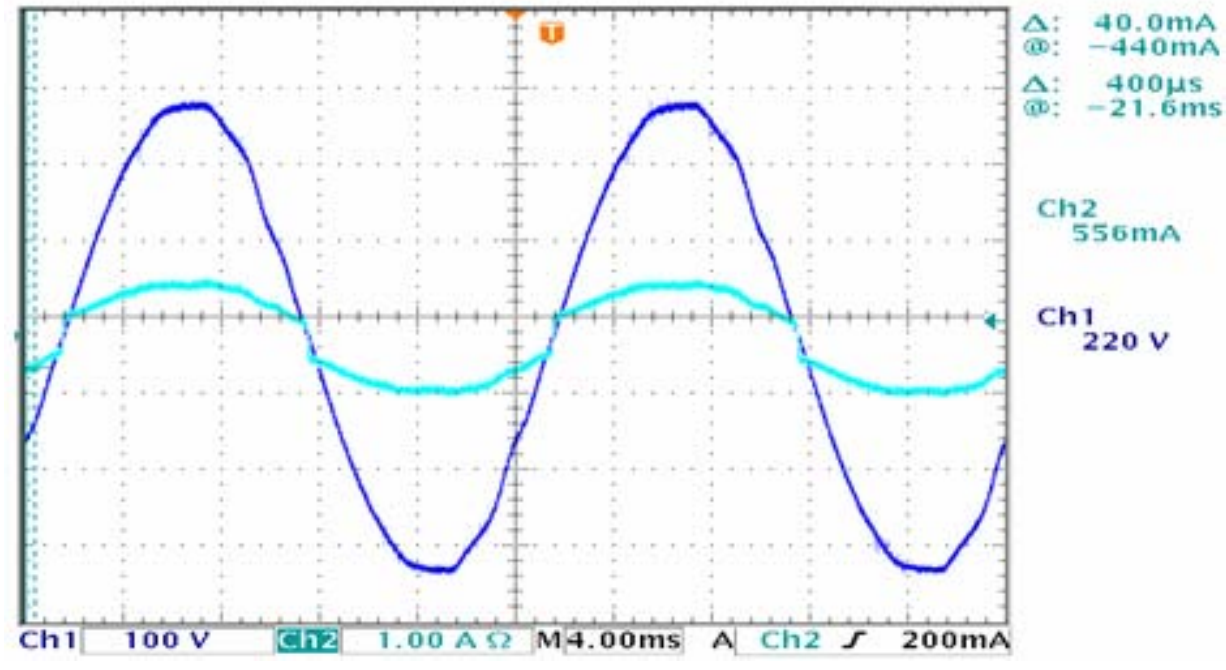

(a) Input voltage: $220 \mathrm{~V}$ (RMS); Input current: $550 \mathrm{~mA}$ (RMS) load: $100 \Omega$; Power factor: 0.974 


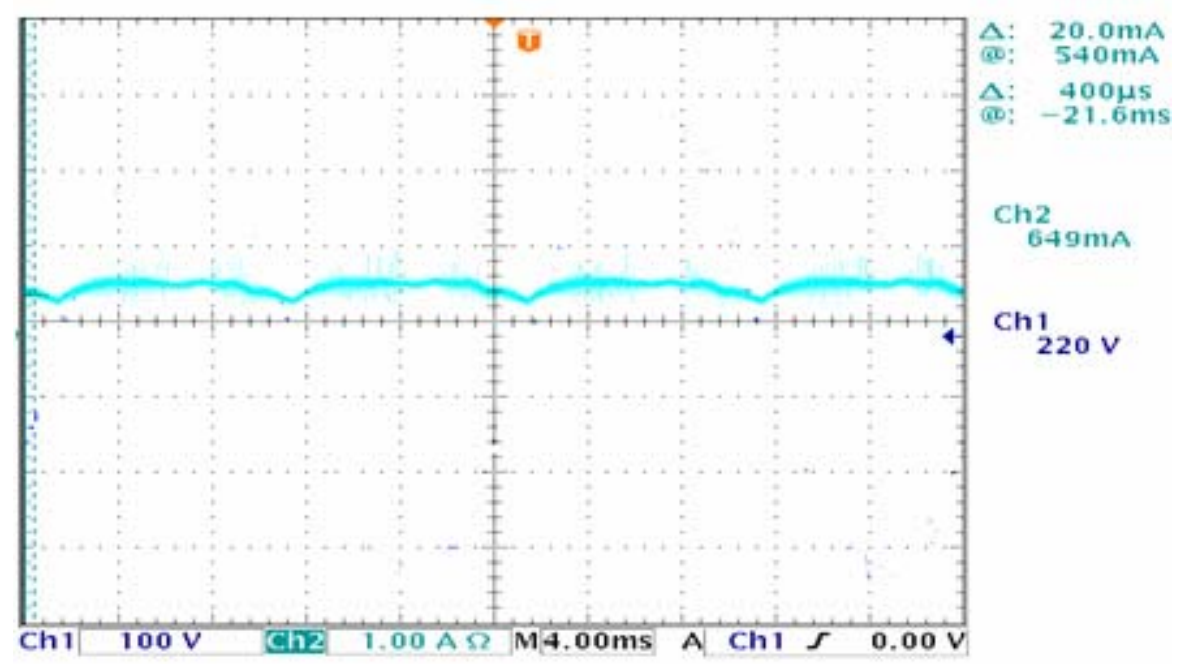

(b) Output current: $1 \mathrm{~A}$

Figure 10. Experimental results.

Therefore, the proposed converter is more suitable for lower output voltage situations such as battery chargers and small output current source inverter induction drives. It appears that such a converter may also be useful for UPS applications, where a current source inverter is preferred in terms of its compatibility with capacitor input loads, such as the cases of personal computers.

\section{REFERENCES}

[1] H. Endo, T. Yamashita and T. Sugiura, "A High-Power-Factor Buck Converter," PESC'92 Record, pp. 1071-1076

[2] H. Mao, Fred C. Lee, Y. jiang and D. Borojevic, "Review of Power Factor Correction Techniques,” IPEMC, 1997, Vol. 11, No. 36.

[3] S. Nonaka and Y. Neba, "Single Phase PWM Current Source Converter with Doublefrequency Parallel Resonance Circuit for DC Smoothing," in Conf. Rec. IEEEIAS Annual.
[4] M. V. Aware and D. sutanto, "Improved Controller for Power Conditioner Using Hightemperature Superconducting Magnetic Energy Storage(HTSSMES)," IEEE Trans. Applied superconductivity, Vol. 13, 2003, p. 3847.

[5] Y. Hayashi, N. Sato and K. Takahashi, "A Novel Control of a Currentsource Active Filter for AC Power System Harmonic Compensation," in Conf Rec. IEEEIAS Annual. Meeting, 1988, pp. 813-819

[6] Y. Ye, Kazerani and V. H. Quintana, "Current Source Converter Based STATCOM: Modeling and Control," IEEE, Trans. Power Delivery, Vol. 20, 2005, pp. 795-800. doi:10.1109/TPWRD.2004.837838

[7] H. Y. Wu, X. M. Yuan, J. F. Zhang and W. X. Lin, "Novel Single Phase Current Source Buck PC with Delta Modulation Control Strategy," in Conf. Publ. Power Electronic and Variable Speed Drives, 6th International Conference, 1996. pp. 138-143.

[8] PHILIP C. TODD, "UC3854 Controlled Power Factor Correction Circuit Design," UNITRODE application note, U134. 